\title{
Condensation oscillations in the peptidization of phenylglycine
}

\author{
Mieczysław Sajewicz' ${ }^{1}$ Monika Gontarska', Dorota Kronenbach¹, Marcin Leda²,3 ${ }^{2}$ Teresa Kowalska', \\ Irving R Epstein ${ }^{2 *}$
}

\begin{abstract}
In earlier studies, we showed that certain low-molecular-weight carboxylic acids (profens, amino acids, hydroxy acids) can undergo spontaneous in vitro chiral conversion accompanied by condensation to from oligomers, and we proposed two simple models to describe these processes. Here, we present the results of investigations using non-chiral high-performance liquid chromatography with diode array detector (HPLC-DAD) and mass spectrometry (MS) on the dynamics of peptidization of $S-, R$-, and rac-phenylglycine dissolved in $70 \%$ aqueous ethanol and stored for times up to one year. The experimental results demonstrate that peptidization of phenylglycine can occur in an oscillatory fashion. We also describe, and carry out simulations with, three models that capture key aspects of the oscillatory condensation and chiral conversion processes.
\end{abstract}

\section{Background}

The remarkable phenomenon of spontaneous in vitro oscillatory chiral conversion of selected profens, amino acids, and hydroxy acids has been the focus of our attention for some time. We first observed oscillatory chiral conversion in selected profens: $S(+)$-ibuprofen, $S$ (+)-naproxen, $S, R( \pm)$-2-phenylpropionic acid, $S(+)$-flurbiprofen, $R(-)$-flurbiprofen, and $S, R( \pm)$-ketoprofen [1-3]. Later we described an analogous behavior in several amino acids: $L$-alanine, $L$ - $\alpha$-phenylalanine, and $L$-tyrosine [4-6]. We have characterized similar phenomena in selected hydroxy acids $[7,8]$ ( $L$-lactic acid, $R$ - $\alpha$-hydroxybutyric acid, $S$ - $\alpha$-hydroxybutyric acid, $R$-mandelic acid, and $S$-mandelic acid) as well. Most of these oscillatory chiral conversions take place with the acid samples dissolved in $70 \%$ aqueous ethanol.

The general scheme of these chiral conversions can be simply summarized as

$$
\text { enantiomer }(+) \rightleftarrows \text { enol } \rightleftarrows \text { enantiomer }(-)
$$

If we consider chiral conversion of selected carboxylic acids in aqueous solution in greater detail, then eq. (1) can be written as [9]:

\footnotetext{
* Correspondence: epstein@brandeis.edu

${ }^{2}$ Chemistry Department, MS 015, Brandeis University, Waltham, MA 024549110, USA

Full list of author information is available at the end of the article
}

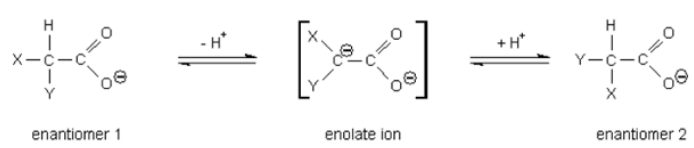

In anhydrous media and in the presence of trace amounts of water, the probable mechanism of chiral conversion is given by eq. (1b) [10]:

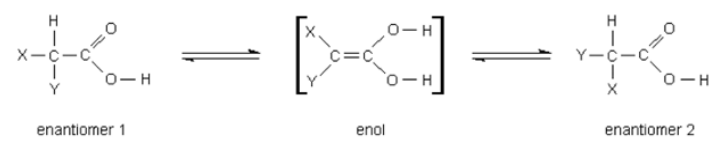

where $\mathrm{X}=-\mathrm{NH}_{2},-\mathrm{OH}$, - Ar, etc., and $\mathrm{Y}=-\mathrm{R}$, etc.

We have suggested two simple models of oscillatory chiral conversion [11]. The simpler model $[5,12]$ is based on autocatalytic dimerization. Oscillations appear in this model in both enantiomer subsystems. Racemization is a linear reversible reaction coupling the two oscillating subsystems. This model is based on the oscillatory Templator model of Peacock-López and collaborators $[13,14]$.

In the second approach [15], oscillations appear as the result of coupling between enantiomers. This model appears particularly relevant for systems involving condensation or peptidization in which the condensate (dipeptide) $S R$ has different chemical properties than $R S$, e.g., where only the residue on the left undergoes epimerization. 
In subsequent papers [16-18], we demonstrated via the biuret test [16] and ${ }^{13} \mathrm{C}$ NMR spectroscopy $[17,18]$ that profens, amino acids, and hydroxy acids can also undergo spontaneous condensation or peptidization when stored for sufficient time in $70 \%$ aqueous ethanol.

Ivanov et al. $[19,20]$ have convincingly documented the oscillatory condensation of organosilanols (e.g., $\mathrm{R}_{2} \mathrm{Si}(\mathrm{OH})_{2}$ or $\left.\mathrm{RR} \mathrm{Ri}^{\prime}(\mathrm{OH})_{2}\right)$. There are several analogies between the results presented in their studies and those found in our own laboratory, which have inspired us to focus on the dynamics of condensation or peptidization of chiral low-molecular-weight carboxylic acids. For this reason, and because of the potential importance of this process in synthetic biology and chemical evolution, we have decided to focus on the issue of peptidization of amino acids coupled to their oscillatory chiral conversion [16]. More specifically, we scrutinize here the dynamics of peptidization of the low-molecular-weight amino acids, $R$-, $S$-, and rac-phenylglycine. The primary analytical tool that we employ to monitor the spontaneous peptidization of phenylglycine samples dissolved in $70 \%$ aqueous ethanol is a non-chiral high-performance liquid chromatographic system with diode-array detection (HPLCDAD). We also supplement this technique with mass spectrometry (MS). In addition, we propose three models that go beyond the schemes developed earlier [11] to capture key aspects of the condensation and oscillatory chiral conversion processes.

We note that Blackmond [21] has suggested a mechanism involving preferential catalysis by homochiral dimers to explain enantiomeric amplification in the Soai reaction, the autocatalytic alkylation of N-heterocyclic aldehydes by zinc dialkyls. Mickskei et al. [22] subsequently extended this idea to a detailed model and showed in numerical simulations that enantiomeric enrichment and oscillation can occur under appropriate conditions.

\section{Experimental Reagents}

$R$-Phenylglycine and $S$-phenylglycine of analytical purity grade were purchased from Sigma-Aldrich (St Louis, MO, USA). Phenylglycine racemate was prepared by mixing optically pure $R$ and $S$ antimers in molar proportions of 1:1. For the spontaneous peptidization experiments, we used solutions of $R$-phenylglycine, $S$ phenylglycine, and rac-phenylglycine in $70 \%$ aqueous ethanol. The concentration of each optically pure enantiomer was $0.5 \mathrm{~g} \mathrm{~L}^{-1}\left(3.3 \times 10^{-3} \mathrm{~mol} \mathrm{~L}^{-1}\right)$. The racemic mixture contained each antimer at half the above concentration. Samples were stored in tightly stoppered colourless glass vials and allowed to age at $22^{\circ} \mathrm{C}$. We also prepared analogous solutions of $R$-phenylglycine,
$S$-phenylglycine, and rac-phenylglycine that were stored for one year at $22^{\circ} \mathrm{C}$.

\section{HPLC-DAD}

High performance liquid chromatographic analysis was carried out using a Gyncotek liquid chromatograph (Gyncotek, Macclesfield, UK) equipped with a Gyncotek Gina 50 model autosampler, Gyncotek P 580A LPG model pump, Gyncotek DAD UVD 340U model diode array detector, and Chromeleon Dionex v. 6.4 software for data acquisition and processing. The analyses were carried out in the isocratic mode, using an RP-18 $(5 \mu \mathrm{m}$ particle size $)$ column $(250 \mathrm{~mm} \times 4.6 \mathrm{~mm}$ i.d.; Varian, Harbor City, CA, USA), and methanol-water $(6: 4, v / v)$

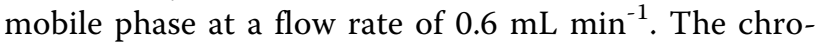
matographic column was thermostated at $35^{\circ} \mathrm{C}$ with a Varian Pro Star 510 model column oven.

\section{Mass Spectrometric Analysis}

Freshly prepared and aged phenylglycine samples were introduced into a Varian 500-MS model mass spectrometer and analyzed in the ESI mode (full ESI-MS scan, positive ionization, spray chamber temperature $45^{\circ} \mathrm{C}$, drying gas temperature $150^{\circ} \mathrm{C}$, drying gas pressure 25 psi, capillary voltage $70 \mathrm{~V}$, needle voltage $5 \mathrm{kV}$ ). A Varian MS Workstation v. 6.9.1 software was used for data acquisition and processing.

\section{Microbiological Tests}

We tested for the presence of microorganisms in samples of $R$ - and $S$-phenylglycine aged for one year using solid and liquid media. Composition of solid medium: meat extract, $2 \mathrm{~g} \mathrm{~L}^{-1}$; yeast extract, $2 \mathrm{~g} \mathrm{~L}^{-1}$, peptone, $5 \mathrm{~g} \mathrm{~L}^{-1}$, sodium chloride, $4 \mathrm{~g} \mathrm{~L}^{-1}$; agar, $15 \mathrm{~g} \mathrm{~L}^{-1}, \mathrm{pH}=$ 7.4. Composition of liquid medium: meat extract, $0.4 \mathrm{~g}$ $\mathrm{L}^{-1}$; enzymatic casein hydrolysate, $5.4 \mathrm{~g} \mathrm{~L}^{-1}$; yeast hydrolysate, $1.7 \mathrm{~g} \mathrm{~L}^{-1}$; peptone, $4.0 \mathrm{~g} \mathrm{~L}^{-1}$; sodium chloride, $3.5 \mathrm{~g} \mathrm{~L}^{-1}$.

With the solid medium, $100-\mu \mathrm{L}$ aliquots of the samples to be tested were introduced and incubated for seven days at approximately the same temperature ( $c a$. $21^{\circ} \mathrm{C}$ ) at which the samples had been stored earlier. This experiment was repeated in triplicate. To $50 \mathrm{~mL}$ of the liquid medium, we added $100-\mu \mathrm{L}$ aliquots and then incubated the samples for fourteen days at ambient temperature $\left(\mathrm{ca} .21^{\circ} \mathrm{C}\right)$ with continuous shaking $(260 \mathrm{rpm})$. This experiment was also repeated in triplicate. In none of the samples was growth of microorganisms observed. Longer incubation periods were not employed, due to the risk of sample infection.

As a control, we carried out a protein determination by the Bradford method [23] and also measured the light absorbance at $\lambda=260 \mathrm{~nm}$ in order to check for the presence of DNA in the two samples. The Bradford 
test gave a negative result, and the spectrophotometric measurement revealed no DNA in our samples. We therefore concluded that no microorganisms were present.

\section{Results and Discussion $S$-Phenylglycine}

In Fig. 1 we present two mass spectra of $S$-phenylglycine, the first of a freshly prepared solution in $70 \%$ aqueous ethanol and the second of an analogous sample after a one-year storage period. Both spectra were recorded for the total samples, i.e., without any preliminary separation by LC-MS.

Considered as fingerprints, the two mass spectra shown in Fig. 1 are quite different. It is evident that fragmentation of the aged sample (Fig. 1b) results in a much richer pattern than that of the freshly prepared one (Fig. 1a). The aged sample apparently contains a wider variety of species. In the fresh sample, the predominant ion appears at $m / z$ 304, which can be ascribed to the $\left[\mathrm{Phg}_{2}+\mathrm{He}\right]^{+}$cation (where $\mathrm{Phg}_{2}$ represents the cyclic associative dimer composed of two phenylglycine molecules coupled by a pair of hydrogen bonds), whereas in the aged sample the same cation makes a relatively small contribution to the recorded fingerprint. The disappearance of this cation supports the notion that the aged sample contains new species originating from $S$-phenylglycine. We note that a second cation (at $m / z=289)$ appears in both spectra. This signal can be attributed to $\left[\mathrm{Phg}_{2}-\mathrm{NH}+\mathrm{He}\right]^{+}$, and in the aged sample it apparently predominates. As this ion, which also seems to be associated with the phenylglycine dimer,

(a)

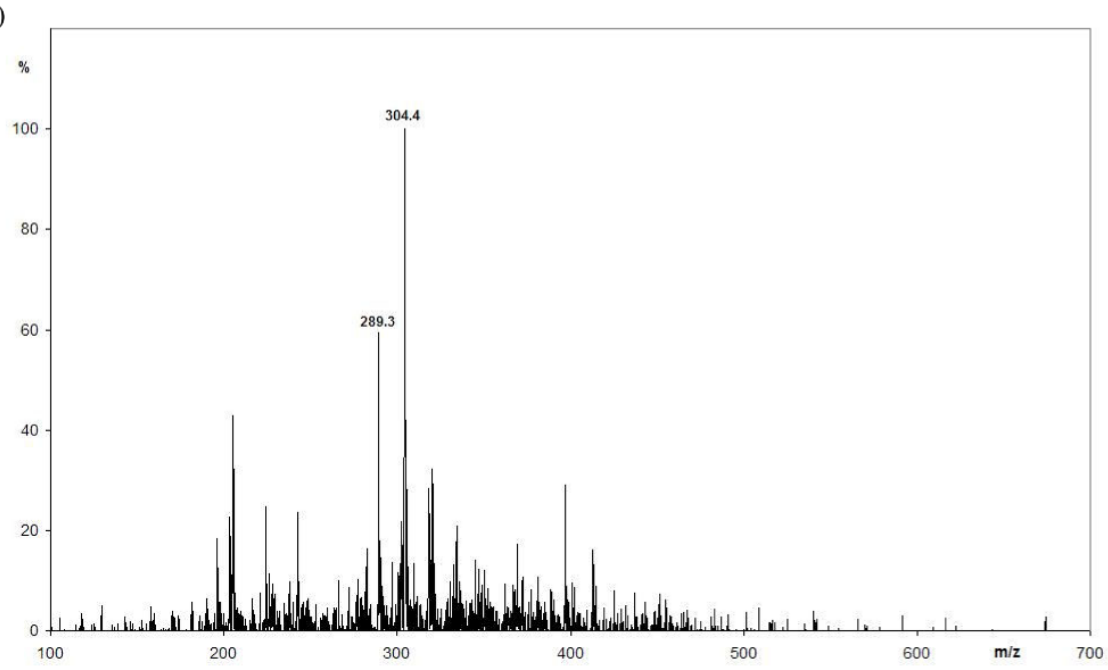

(b)

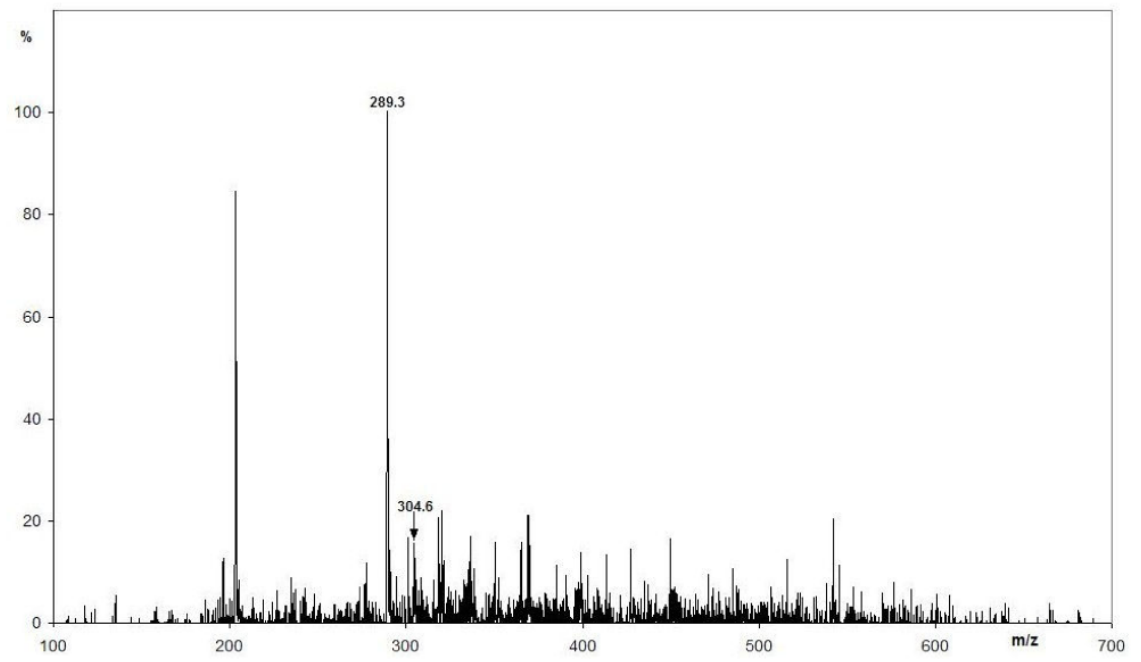

Figure 1 Mass spectra of $S$-phenylglycine solution in $70 \%$ aqueous ethanol; (a) freshly prepared sample, and (b) sample after one year storage period. Both samples were stored at $22^{\circ} \mathrm{C}$. 
still predominates in the sample stored for one year, we conclude that structural transformation due to aging consumes a relatively small portion of the starting material.

The aging of $S$-phenylglycine dissolved in $70 \%$ aqueous ethanol is also mirrored in the respective chromatograms. Based on the results of biuret test [16], it seems that oligopeptides are the most probable outcome of this process. We compare the chromatograms of the freshly prepared $S$-phenylglycine solution with those stored for nine days and for one year (Fig. 2a-c).

In the HPLC experiment, we employ a non-chiral chromatographic system and focus on monitoring the appearance and/or concentration changes of species that evolve during the $S$-phenylglycine aging process. Peaks 1 and 2, which are present in all the samples, with retention times, $\mathrm{t}_{R}$, of 5.2 and $5.4 \mathrm{~min}$, respectively, can probably be attributed to phenylglycine in two different associative forms. We make this assertion because a) the two peaks appear at similar retention times, suggesting similar chemical properties; b) they predominate in the freshly prepared sample; and c) their intensities decrease with time. The mass spectrometric evidence of two species apparently derived from phenylglycine at $\mathrm{m} / z 289$ and 304, which we ascribed earlier to the $\left[\mathrm{Phg}_{2}-\mathrm{NH}+\right.$ $\mathrm{He}]^{+}$and $\left[\mathrm{Phg}_{2}+\mathrm{He}\right]^{+}$cations, respectively, also supports our identification. A key feature, seen in the mass spectra shown in Fig. 1, is that the peaks evolve at different rates, which supports our hypothesis that $S$-phenylglycine appears in the system in two different associative forms.

We attribute the peaks with higher retention times to larger oligopeptides generated in the course of the sample aging. The results of the biuret test performed with $S-, R$-, and rac-phenylglycine [16] also indicate the presence of oligopeptides in aged samples.

In Fig. 3, we present chromatograms of a freshly prepared $S$-phenylglycine solution and one stored for a year. The aim of this comparison is to emphasize the differences at higher retention times, where the higher oligopeptides (which are not abundant enough to be seen in the nine-day sample) are likely to be found.

Figure 3, and the absence of long retention time peaks after nine days, demonstrate that the accumulation of higher oligopeptides is a relatively slow process that may take months to yield measurable amounts of these condensation products. In the insets of Fig. 3b, we examine the peaks corresponding to the three species with the highest retention times in more detail. The different shapes of the UV spectra at different wavelengths and the observed bathochromic shifts support our association of longer retention times with more monomer units in the oligopeptide.

One goal of this study is to establish if the condensation products, i.e., oligopeptides, in an $S$-phenylglycine solution arise in a monotonic or an oscillatory manner. To investigate this question, we monitored chromatographic peak heights in an aging sample, as registered at $275 \mathrm{~nm}$. These peak heights are roughly proportional to the concentrations of the respective chemical species. In Fig. 4, we present the time courses of peaks 1-5, numbered as in Fig. 2.

Clearly, the peak heights change in a non-monotonic fashion. The linear correlation coefficients $r$ for calibration curves determined from the peak heights for stable reference compounds using the same chromatographic conditions (HPLC-DAD system, chromatographic column and mobile phase composition) and at least ten data points always exceeded $r \geq 0.99$. Moreover, the percent error on each individual peak height never surpassed $\pm 5 \%$. Thus, the trends of the peak height changes in Figs. 4a, b seem to confirm the oscillatory nature of the condensation process, though the limited time resolution precludes our establishing whether the reaction is truly periodic.

The height of peak 1 initially rises in an erratic manner. This growth may arise from hydrolysis of trace amounts of oligopeptide impurities present in the commercial sample and visible in the chromatogram in Fig. 2a. After ca. $110 \mathrm{~h}$, the mean abundance of peak 1 starts to decrease in an oscillatory fashion, which can be ascribed to consumption of the starting amino acid through peptidization. This effect correlates with the time-dependent fall of the intensity of peak 1 seen in Figs 2a-c.

The mean intensity of peak 2 grows during the nine day observation period. Again, this behavior may result from hydrolysis of trace oligopeptide impurities or perhaps from interconversion of the two types of $\mathrm{H}$-bonded phenylglycine dimers represented by peaks 1 and 2 . Although the intensity of peak 2 increases during this intial nine-day period (see Figs $2 \mathrm{a}, \mathrm{b}$ ), after one year the intensity of peak 2 becomes almost negligible (see Fig. 2c). This eventual lowering of the intensity of peak 2 may correspond to the consumption of the phenylglycine through peptidization.

Peaks 3-5 can be attributed to oligopeptides initially present in our samples. During the nine days of our experiment, the general trend in the height of peaks 3 and 5 is oscillatory yet growing, while peak 4 is nonmonotonically diminishing. The long-term history of peaks 3-5 confirms a slow concentration growth of the respective oligopeptides (see Figs 2a-c). 


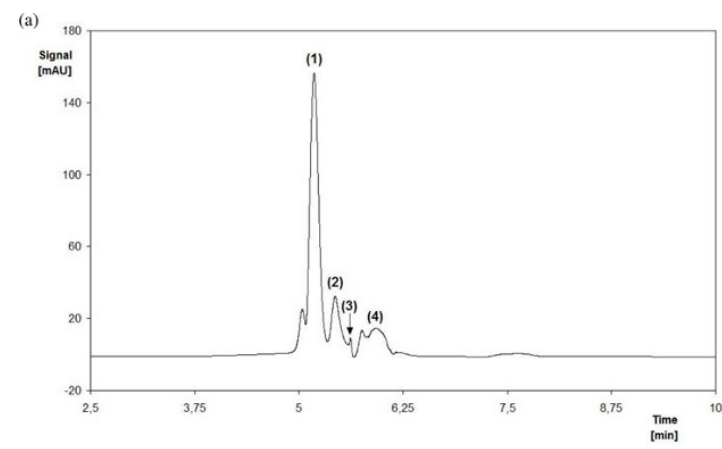

(b)

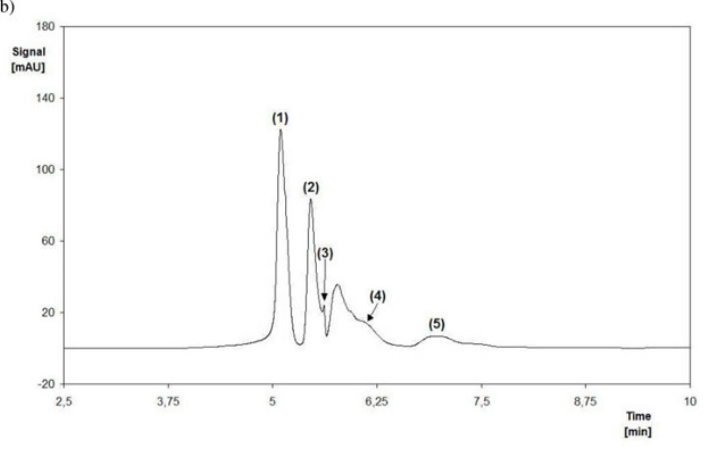

(c)

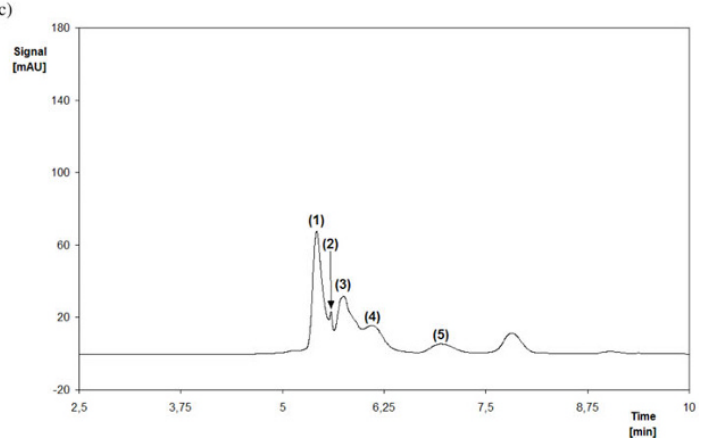

Figure 2 Chromatograms of S-phenylglycine solutions in $70 \%$ aqueous ethanol registered at $275 \mathrm{~nm}$; (a) freshly prepared sample, (b) sample after nine days storage, and (c) sample after one year storage. All samples were stored at $22^{\circ} \mathrm{C}$.

The results presented in Fig. 4 support the oscillatory nature of $S$-phenylglycine peptidization. This oscillatory process can be schematically described by the following equations:

dipeptide $\rightleftarrows 2$ monomeric Phg

tripeptide $\rightleftarrows$ monomeric Phg + dipeptide

$\mathrm{n}$ - oligopeptide $\rightleftarrows$ monomeric Phg $+(\mathrm{n}-1)$ - oligopeptide

\section{$R$-Phenylglycine and rac-Phenylglycine}

We repeated our experimental protocol with samples of $R$-phenylglycine and rac-phenylglycine, recording mass spectra for freshly prepared solutions in $70 \%$ aqueous ethanol and for the analogous samples after a one year storage period. All spectra were recorded for the total samples, i.e., without preliminary separation and identification of any of the aging products by LC-MS. The results obtained are shown in Figs. 5 and 6.

As with the $S$-enantiomer, the mass spectrometric fingerprints of the freshly prepared and aged $R$ - and rac-phenylglycine samples differ considerably. Again, both samples show peaks at $m / z 289$ and 301, which we attribute to two different dimeric forms of the starting material. Again, the relative intensities of these two signals change in the course of aging so that in the freshly prepared samples the peak at $m / z 289$ is lower than that of the heavier ion, while after one year the reverse proportion is observed.

The mass spectra of the aged $R$ - and rac-phenylglycine samples (Figs. 5b and 6b) differ, however, in important ways from that of the aged $S$ species (Fig. 1b). In the latter case, we find a much richer array of signals originating from heavier ions than in the mass spectrum of the freshly prepared sample (see Fig. 1b vs. 1a). In the first two cases, the spectrum of the aged solution contains fewer, better separated signals at $\mathrm{m} / \mathrm{z}$ values above those attributed to the $\mathrm{H}$-bonded dimers than in the starting solution. In the aged $R$-phenylglycine sample, for example, two such signals are perceptible at $m / z 413$ and 582 (Fig. 5b). The mass values suggest that all these signals might originate, e.g., from the fragmented tetrapeptide. The analogous signals found in the aged rac-phenylglycine sample appear at $\mathrm{m} / z 369,413$, and 542 (Fig. 6b) and hence an analogous conclusion as to a possible tetrapeptide origin can be drawn.

We also monitored the aging process with $R$-phenylglycine and rac-phenylglycine by means of HPLC-DAD using the same techniques we applied to $S$-phenylglycine. In qualitative terms, the behavior of all three sets of samples was very similar. Again, we observed the two peaks ( 1 and 2) at retention times $\left(t_{\mathrm{R}}\right)$ of 5.2 and 5.4 $\mathrm{min}$, respectively, which we ascribe to pure $R$ - and rac-phenylglycine in the two different associative forms. However, more detailed scrutiny of the respective chromatograms reveals quantitative differences that point toward a different dynamics of aging, i.e., of peptidization, in each of the three samples. A comparison of the respective chromatograms is given in Fig. 7.

Figure 7a demonstrates that the intensities of peaks 1 and 2 differ among the three samples after seven days of aging. These intensities and their ratios are, respectively, 
(a)

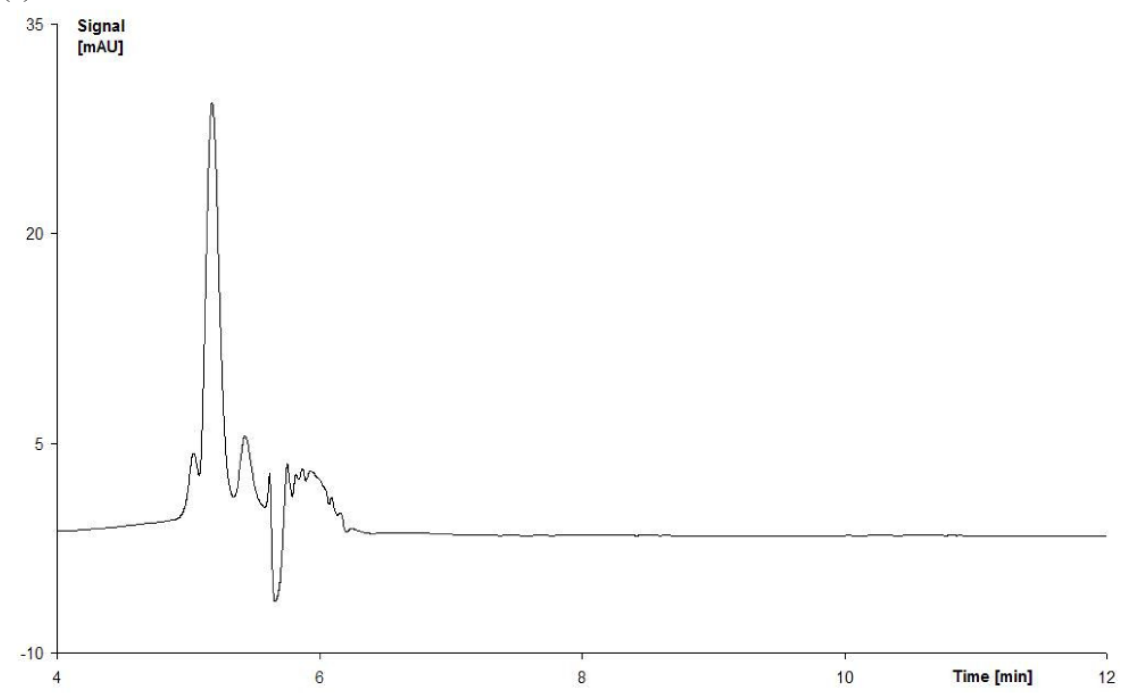

(b)

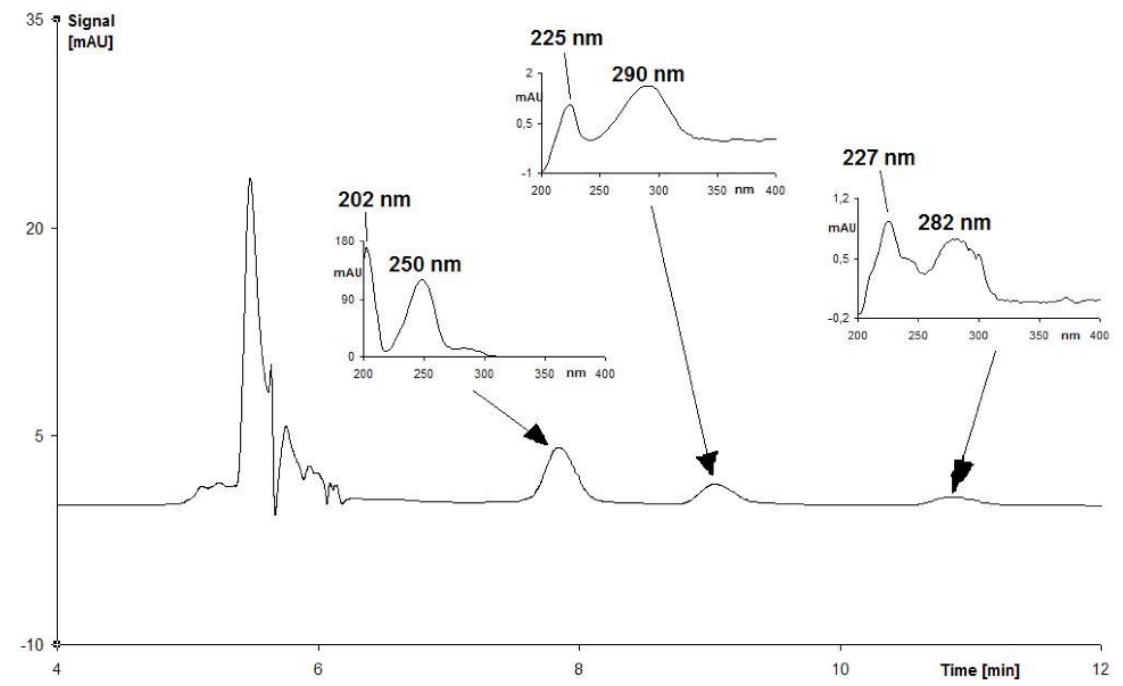

Figure $\mathbf{3}$ Chromatograms of an S-phenylglycine solution in $\mathbf{7 0 \%}$ aqueous ethanol registered at $\mathbf{3 0 0} \mathbf{n m}$. (a) freshly prepared sample; (b) sample after one year. Insets in (b) show UV spectra of the separated species recorded near the maxima of the respective peaks.

112 and $75 \mathrm{mAV}$ (1.49:1), 97 and 54 mAV (1.80:1). and 81 and $29 \mathrm{mAV}$ (2.79:1) for $S$-phenylglycine, $R$-phenylglycine, and rac-phenylglycine, respectively. We find that the lowest concentrations of species 1 and 2, and hence the highest peptidization rate, occur in the case of the racemic mixture. This observation is in good agreement with the results of biuret test [16] performed on three different phenylglycine samples after a storage period of a few days, which also pointed to rac-phenylglycine as the sample with the highest peptidization yields.

The chromatograms obtained after a one year storage period (Fig. 7b) present a somewhat different picture.
The intensities of peaks 1 and 2 and their ratios with $S$ phenylglycine, $R$-phenylglycine, and rac-phenylglycine, respectively, are now 65 and $11 \mathrm{mAV}$ (ratio 5.91), 155 and $50 \mathrm{mAV}$ (3.10), and 169 and $19 \mathrm{mAV}$ (8.63). Clearly, the long term dynamics differ from what was observed after seven days. To highlight the differences in the long term peptidization process with the three samples, in Fig. 8 we expand the chromatograms shown in Fig. $7 \mathrm{~b}$ in the 6-12 min retention time range.

Figure 8 demonstrates that after one year higher molecular weight products, presumably oligopeptides, which cannot be detected during the short term storage period, appear. The peak numbering corresponds to that used in 
(a)

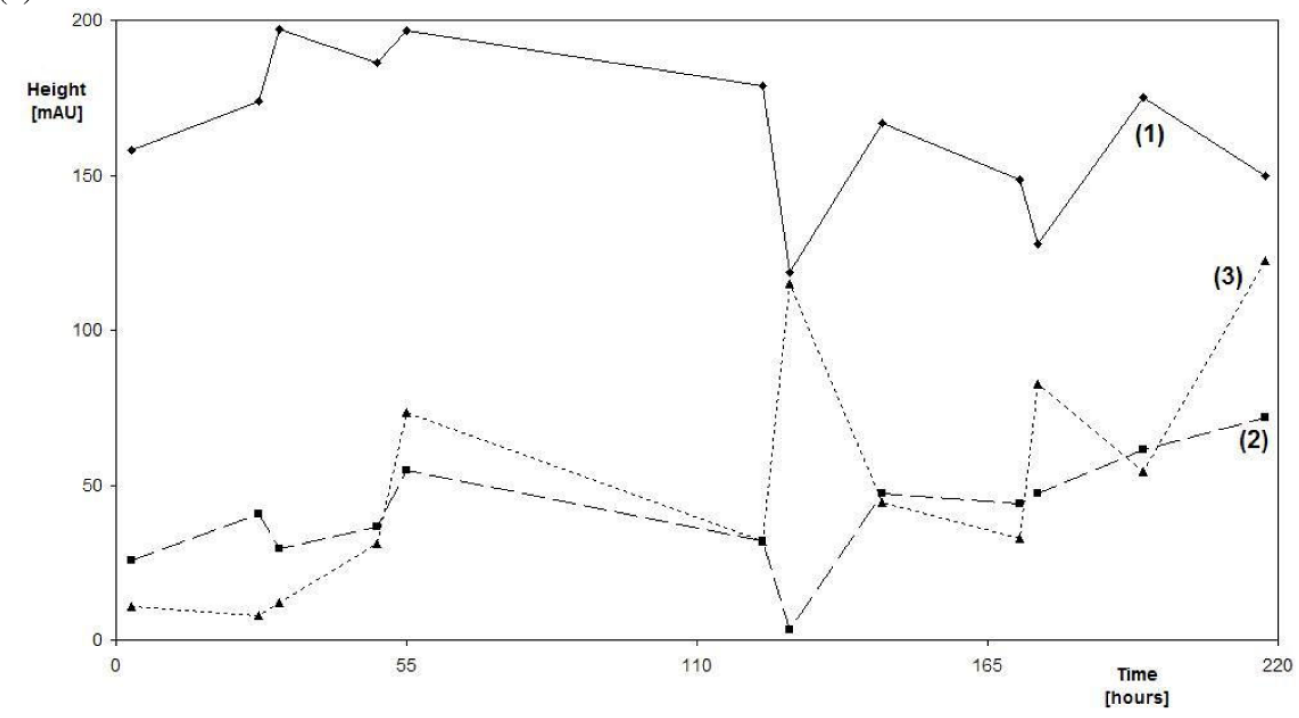

(b)

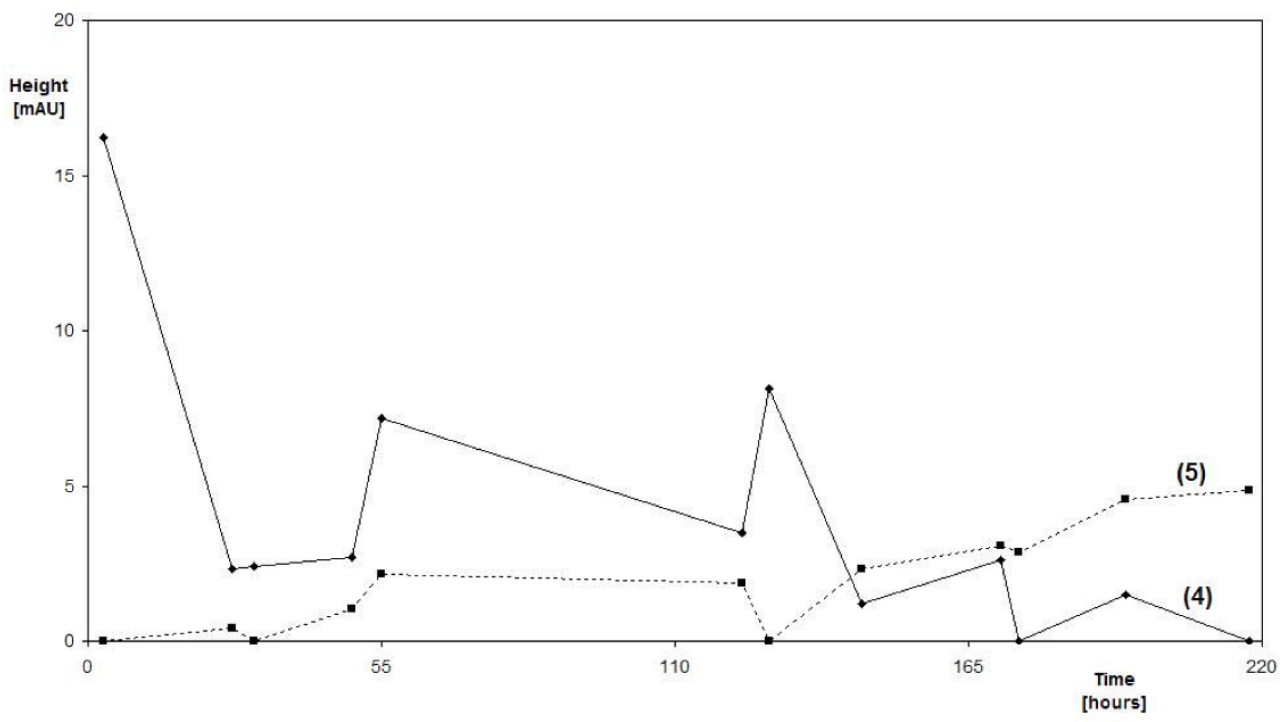

Figure 4 Chromatographic peak heights for (a) peaks $1-3$, and (b) peaks 4 and 5 for an S-phenylglycine solution stored at $22^{\circ} \mathrm{C}$ for nine days. Peak numbers as in Fig. 2. Retention times: peak 1, 5.2 min; peak 2, 5.4 min; peak 3, 5.6 min; peak 4, 6.0 min; peak 5, 6.9 min.

Fig. 2, but we now see the additional aging products numbered 6 to 9 . Each one year old sample yields different amounts of the respective products, and in the aged $R$ phenylglycine sample peaks 4 and 5 are no longer visible.

Since a major focus of this study is on establishing whether the peptidization process is monotonic or oscillatory, we used the HPLC data to follow the concentrations of the various species originating from $R$ phenylglycine and rac-phenylglycine in time. The results for peak heights 1-5, which should be roughly proportional to the concentrations of the corresponding species are shown for $R$-phenylglycine and rac-phenylglycine in Figs. 9 and 10, respectively. Although the long times between measurements make it difficult to obtain a characteristic frequency of oscillation, it is clear that the behavior is not monotonic.

\section{Theoretical Models}

We present here three models derived from existing schemes in the literature that capture the key features of the processes studied here: chiral conversion and condensation occurring in an oscillatory fashion. 
(a)

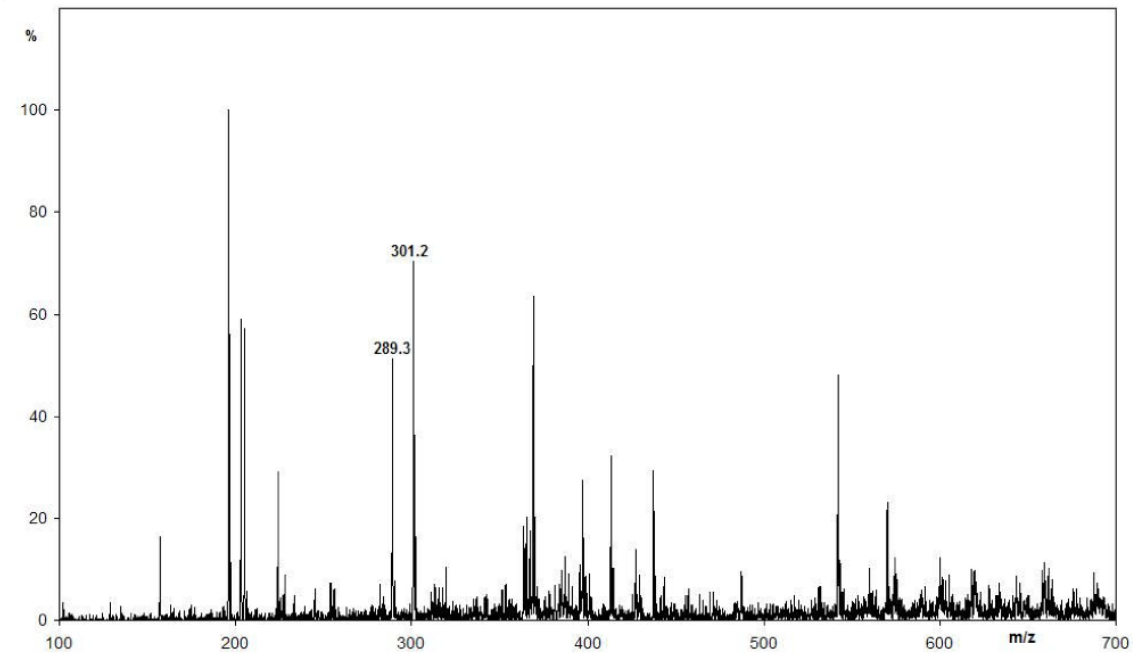

(b)

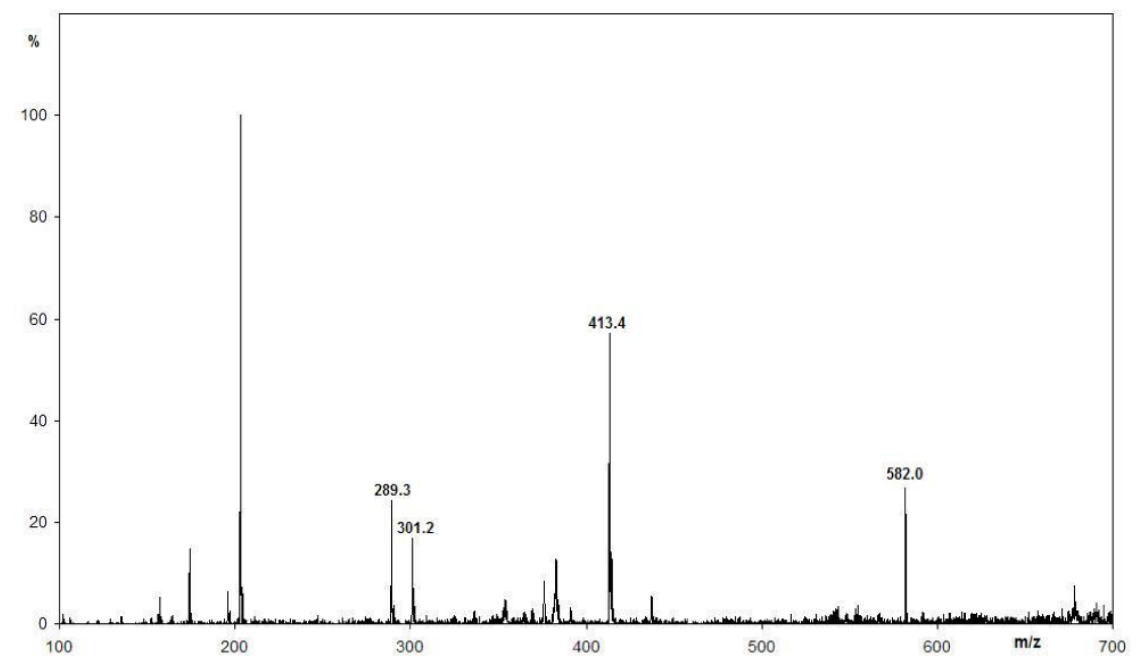

Figure 5 Mass spectra of $R$-phenylglycine solutions in $70 \%$ aqueous ethanol; (a) freshly prepared sample, and (b) sample after one year storage. Both samples were stored at $22^{\circ} \mathrm{C}$.

Model 1

We wish to describe a chiral system in which association can occur. Suppose that enatiomeric monomers $S$ and $\mathrm{R}$ can form dimers $\left(\mathrm{S}_{2}, \mathrm{R}_{2}\right)$, trimers and higher oligomers $\left(\mathrm{S}_{\mathrm{i}}, \mathrm{R}_{\mathrm{i}} \mathrm{i}=4, \ldots\right)$. Including all possible association and dissociation reactions generates a very complicated network, but it is possible to choose a subsystem that gives temporal oscillation. One such possibility (for an achiral system) has been proposed by Hyver [24], and we modify his scheme to include chirality.

$$
\begin{aligned}
& 2 \mathrm{~S} \longleftarrow \text { k1 } \mathrm{S}_{2} \quad 2 \mathrm{R} \longleftarrow \mathrm{R}_{2} \mathrm{R}_{2} \\
& 2 \mathrm{~S}_{2} \longleftarrow \text { k2 } \mathrm{S}_{4} \quad 2 \mathrm{R}_{2} \longleftarrow \text { k2 } \mathrm{R}_{4}
\end{aligned}
$$

$$
\begin{aligned}
& 2 \mathrm{~S}_{4} \stackrel{k 3}{\longleftarrow} \mathrm{S}_{8} \quad \mathrm{R}_{4} \longleftarrow \text { k3 } \mathrm{R}_{8} \\
& \mathrm{~S}+\mathrm{S}_{8} \stackrel{k 4}{\longleftarrow} \mathrm{S}_{9} \\
& \mathrm{x} \stackrel{k s}{\longrightarrow} \mathrm{S}_{8} \\
& \mathrm{~S} \underset{k-5}{\stackrel{k 5}{\rightleftarrows} \mathrm{R}}
\end{aligned}
$$

Reaction (8) represents racemization, which is assumed to be first order and slow with respect to the other reactions. This scheme contains no autocatalytic 


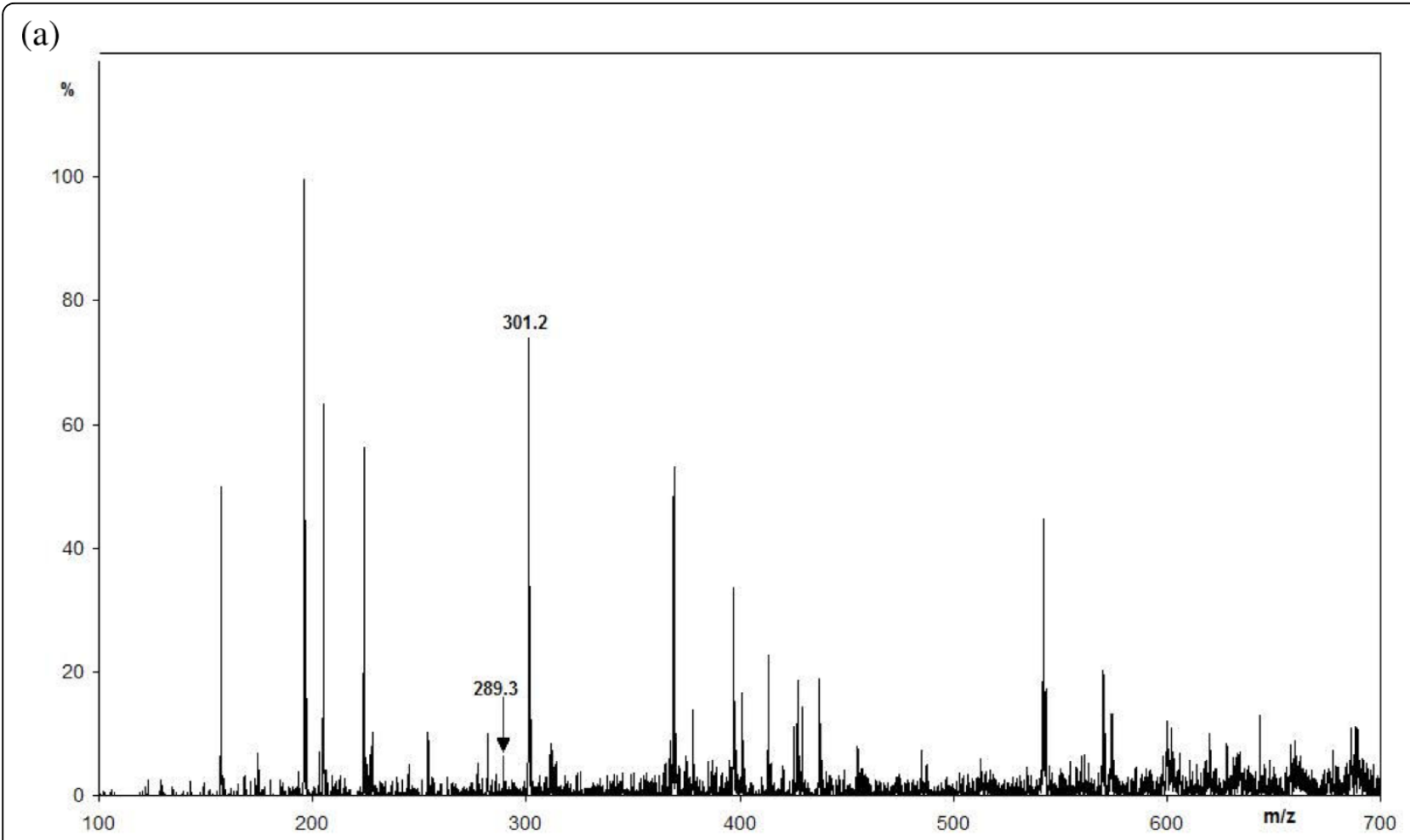

(b)

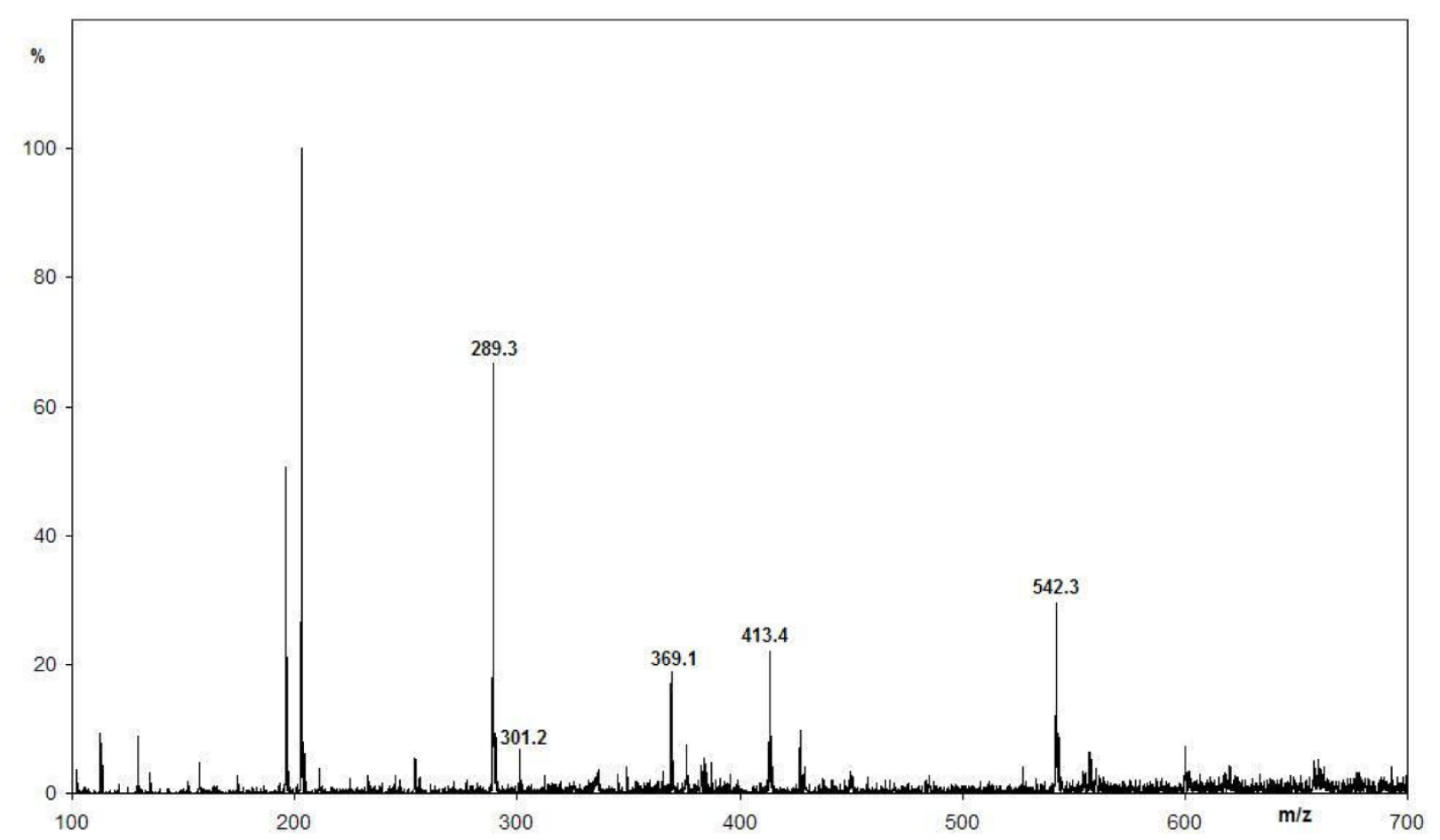

Figure 6 Mass spectra of rac-phenylglycine solutions in $70 \%$ aqueous ethanol; (a) freshly prepared sample, and (b) sample after one year storage. Both samples were stored at $22^{\circ} \mathrm{C}$. 
(a)

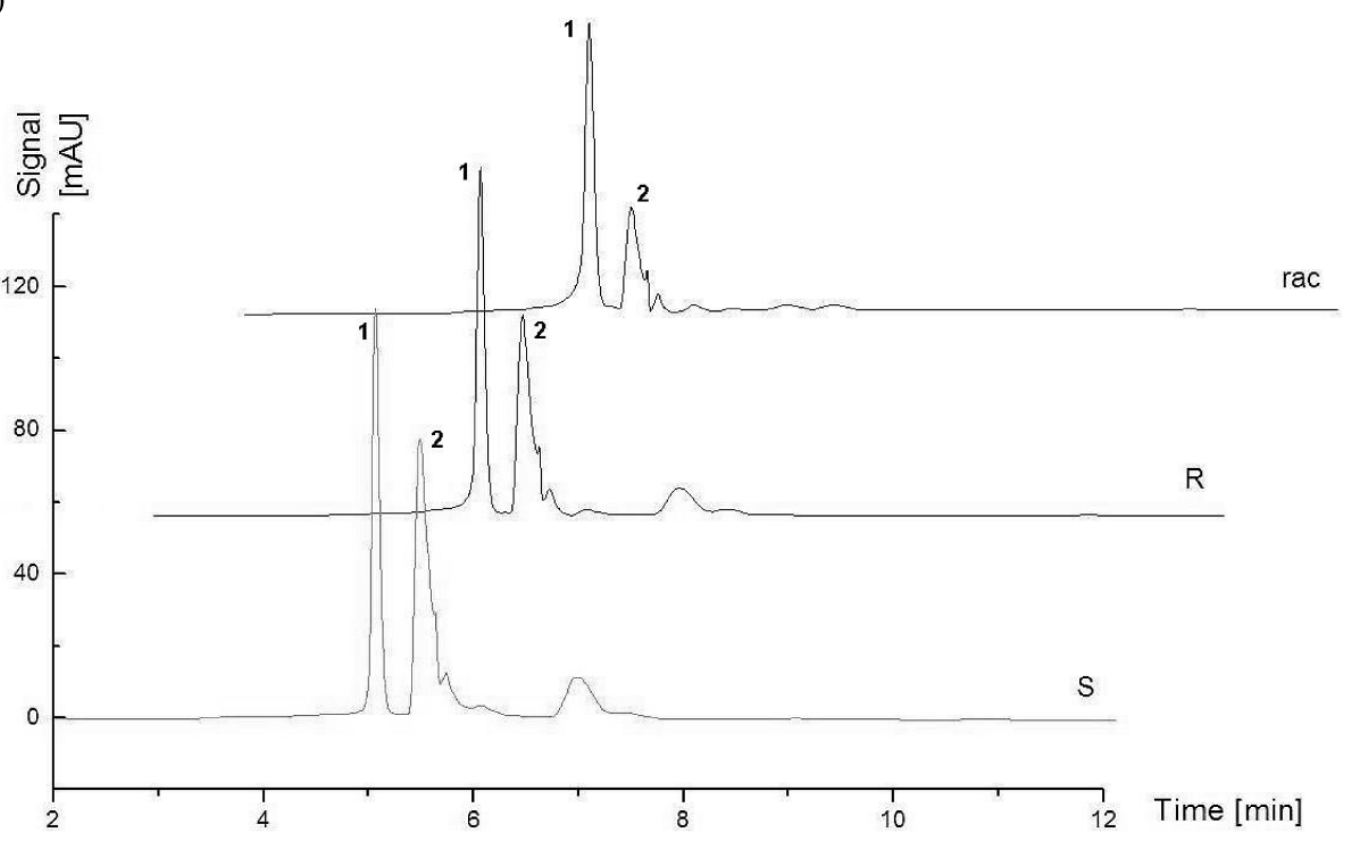

(b)

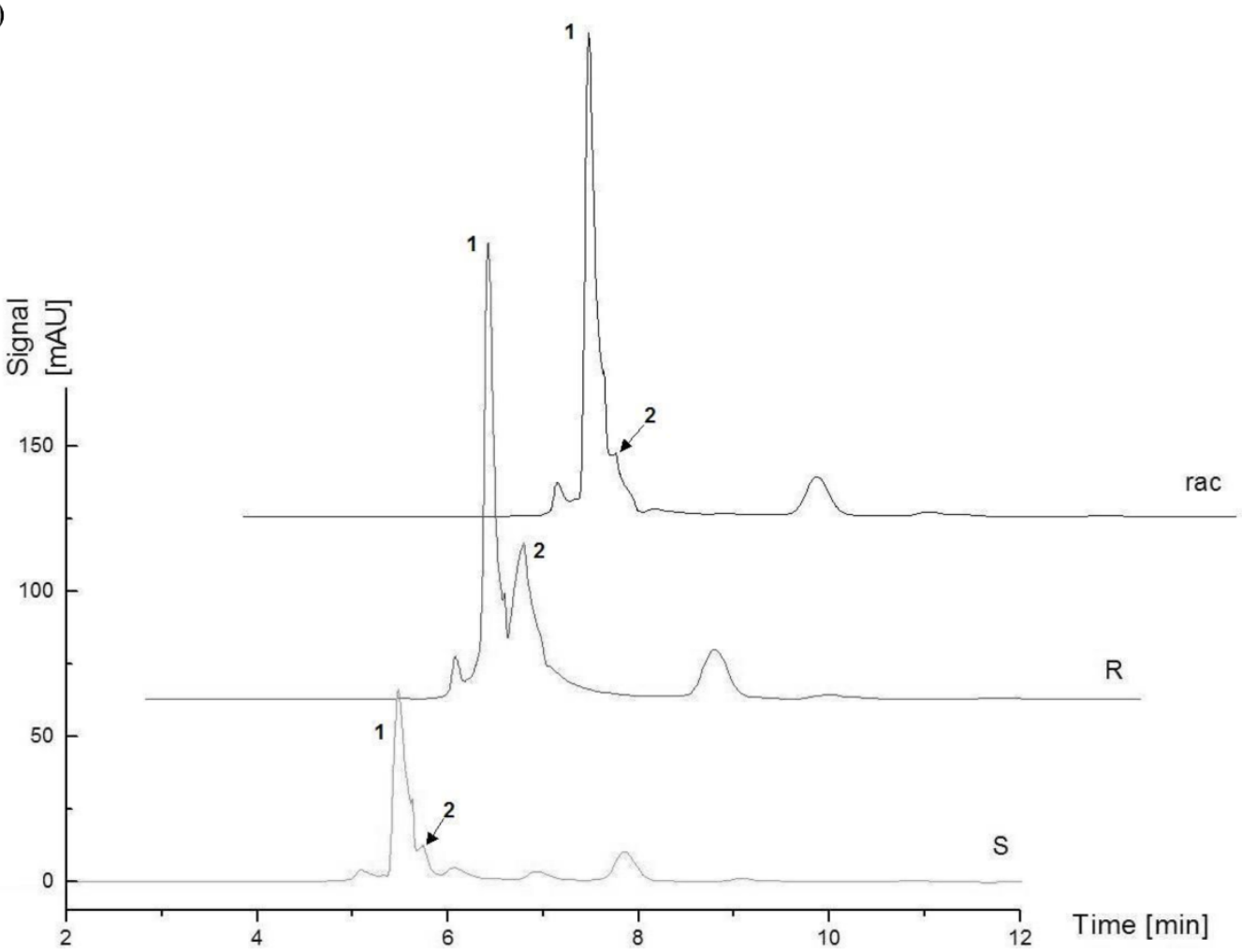

Figure 7 Chromatograms of $S$-phenylglycine, $R$-phenylglycine, and rac-phenylglycine solutions in $70 \%$ aqueous ethanol registered at $275 \mathrm{~nm}$; (a) each sample after seven days storage; (b) each sample after one year storage. All samples were stored at $22^{\circ} \mathrm{C}$. 
steps. The system is open by virtue of the pool of higher oligomers $(\mathrm{X})$, which dissociate to create lower oligomers. This pool of oligomers need not contain equal amounts of enantiomers, so the rate constants $k_{r}$ and $k_{s}$ can be different. To take into account the condensation of monomers, we add to Hyver's scheme the additional steps

$$
2 \mathrm{~S} \underset{k-6}{\stackrel{k 6}{\rightleftarrows}} \mathrm{S}_{2}{ }^{\prime} \quad 2 \mathrm{R} \underset{k-6}{\stackrel{k 6}{\rightleftarrows}} \mathrm{R}_{2}{ }^{\prime} \quad \mathrm{R}+\mathrm{S} \underset{k-6}{\stackrel{k 6}{\rightleftarrows}} \mathrm{RS}
$$

where $S_{2}{ }^{\prime}, R_{2}$ ' and RS denote condensates of enantiomers $\mathrm{S}$ and $\mathrm{R}$. We assume that reactions involving condensates (9) are much slower than dissociations (3-7). As Fig. 11 shows, oscillations are easily obtained in such a model.

\section{Model 2}

In an alternative approach, the condensation step itself can be the source of nonlinearity. In the model shown below [25] formation of activated monomers $S^{*}$ and $R^{*}$ occurs autocatalytically (reaction 11).

$$
\begin{array}{ll}
\mathrm{S} \underset{k-1}{\stackrel{k 1}{\rightleftarrows} \mathrm{S}^{*}} & \mathrm{R} \underset{k-1}{\stackrel{k 1}{\rightleftarrows} \mathrm{R}^{*}} \\
\mathrm{~S}+2 \mathrm{~S}^{*} \stackrel{k 2}{\longrightarrow} 3 \mathrm{~S}^{*} & \mathrm{R}+2 \mathrm{R}^{*} \stackrel{k 2}{\longrightarrow} 3 \mathrm{R}^{*}
\end{array}
$$

$$
\begin{aligned}
& \mathrm{S}+\mathrm{S} * \underset{k-3}{\stackrel{k 3}{\rightleftarrows}} \mathrm{S}_{2} \quad \mathrm{R}+\mathrm{R} * \underset{k-3}{\stackrel{K 3}{\rightleftarrows}} \mathrm{R}_{2} \\
& \mathrm{~S}_{2}+\mathrm{S}^{*} \underset{k-4}{\stackrel{k 4}{\rightleftarrows}} \mathrm{S}_{3} \quad \mathrm{R}_{2}+\mathrm{R}^{*} \underset{k-4}{\stackrel{k 4}{\rightleftarrows}} \mathrm{R}_{3} \\
& \mathrm{~S}+\mathrm{R} * \stackrel{k 5}{\longrightarrow} \mathrm{SR} \quad \mathrm{SR}+\mathrm{R} \stackrel{k 5}{\longrightarrow} \mathrm{SR} \\
& \mathrm{SR} \stackrel{k 6}{\longrightarrow} \mathrm{S}+\mathrm{R}
\end{aligned}
$$

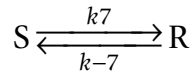

This scheme is closed with respect to mass exchange, i.e., the total concentration of monomers $c=[\mathrm{S}]+\left[\mathrm{S}^{*}\right]$ $+2\left[S_{2}\right]+3\left[S_{3}\right]+[R]+\left[R^{*}\right]+2\left[R_{2}\right]+3\left[R_{3}\right]$ is constant.

The dimer and trimer concentrations in Fig. 12 oscillate with small amplitude. In such a system, it is likely that only oscillations in the monomer concentrations would be observable.

\section{Model 3}

In our final model, oscillations appear as result of coupling between enantiomers[15]. This model is especially

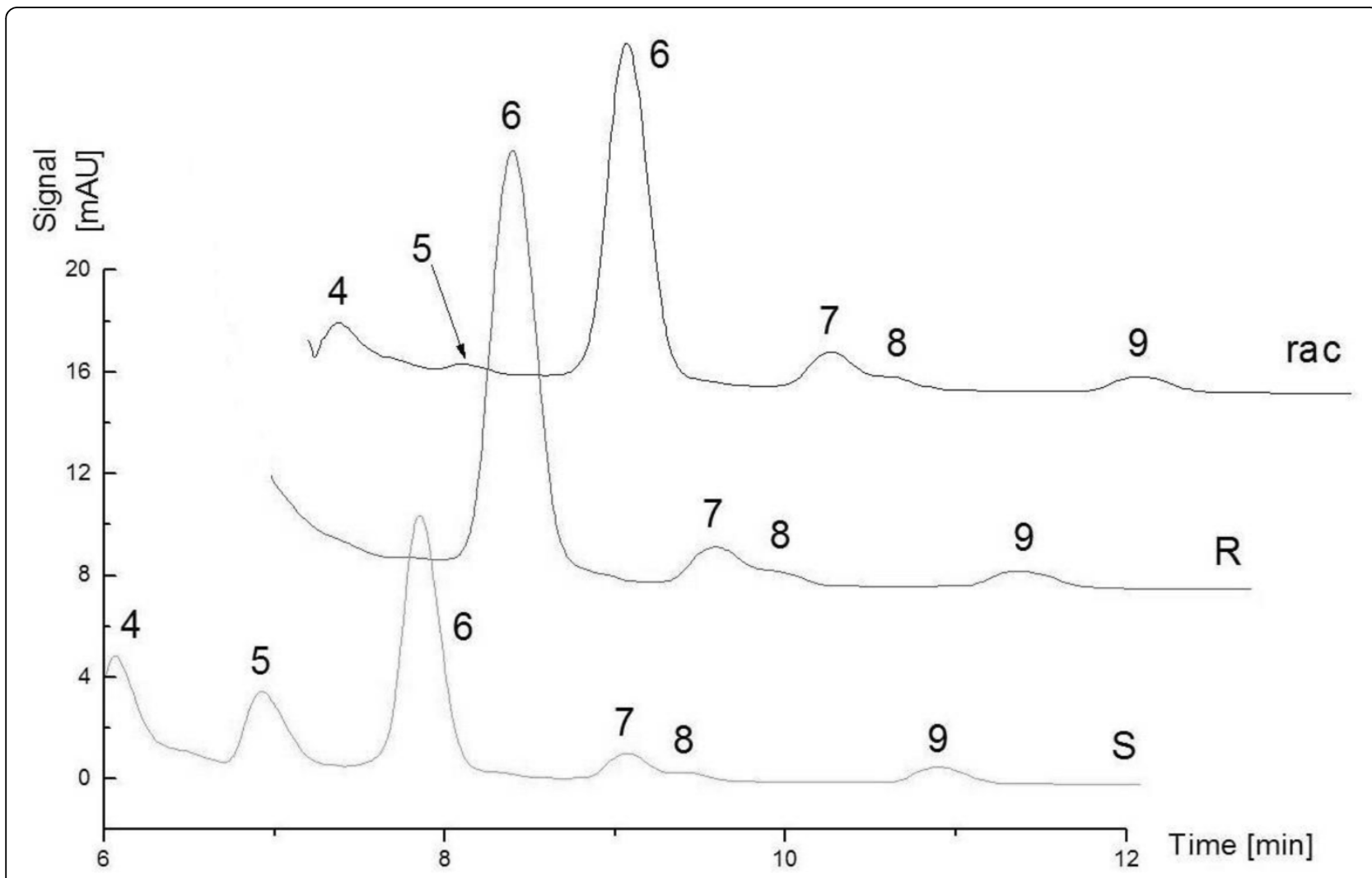

Figure 8 Chromatograms of S-phenylglycine, $R$-phenylglycine, and rac-phenylglycine solutions in $70 \%$ aqueous ethanol at $275 \mathrm{~nm}$. 
(a)

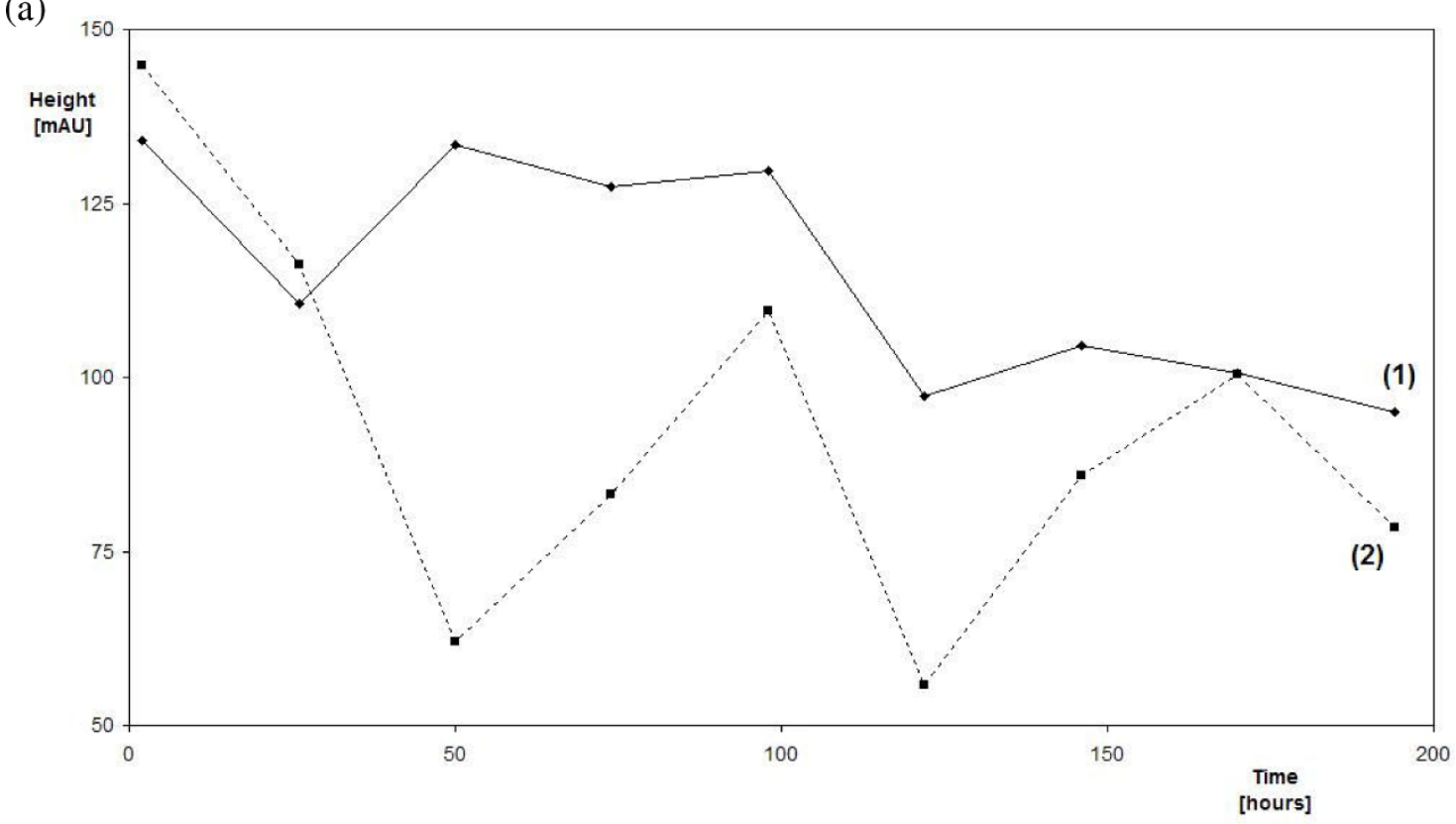

(b)

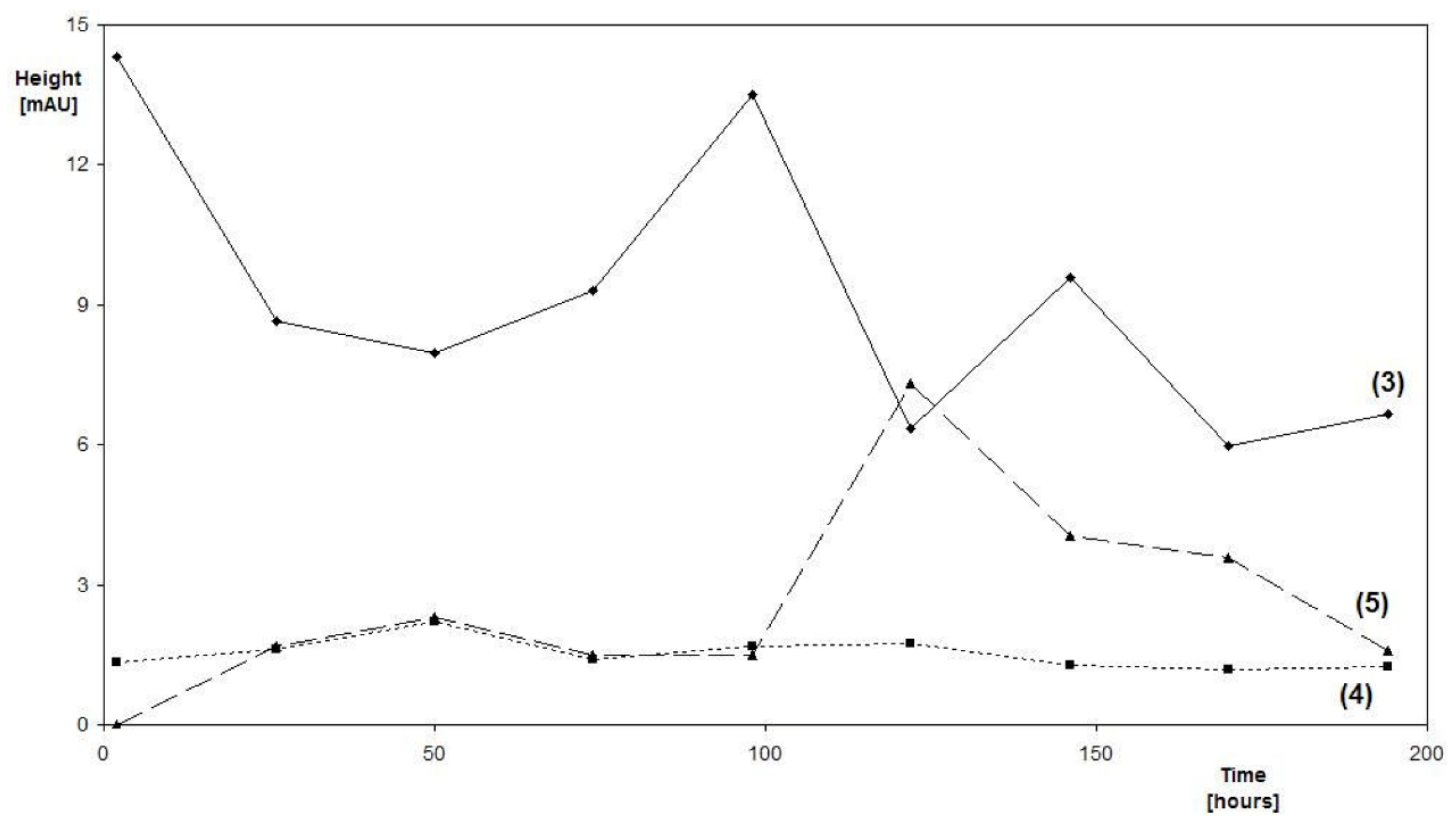

Figure 9 Chromatographic peak heights for (a) peaks 1 and 2, and (b) peaks 3-5 for an $R$-phenylglycine solution stored at $22^{\circ} \mathrm{C}$ for nine days. Peak numbers as in Fig. 2. Retention times: peak 1, 5.2 min; peak 2, 5.4 min; peak 3, 5.6 min; peak 4, 6.0 min; peak 5, 6.9 min.

appropriate for systems in which the condensate SR has different chemical properties than RS.

$$
\begin{array}{ll}
\mathrm{R} \underset{k-1}{\stackrel{k 1}{\rightleftarrows}} \mathrm{R}^{*} & \mathrm{~S} \underset{k-1}{\stackrel{k 1}{\rightleftarrows} \mathrm{S}^{*}} \\
\mathrm{R}^{*}+\mathrm{R} \stackrel{k 2}{\longrightarrow} \mathrm{R}_{2} & \mathrm{~S}^{*}+\mathrm{S} \stackrel{k 2}{\longrightarrow} \mathrm{S}_{2}
\end{array}
$$

$$
\mathrm{S}_{2} \stackrel{k 3}{\longrightarrow} 2 \mathrm{~S}
$$


(a)

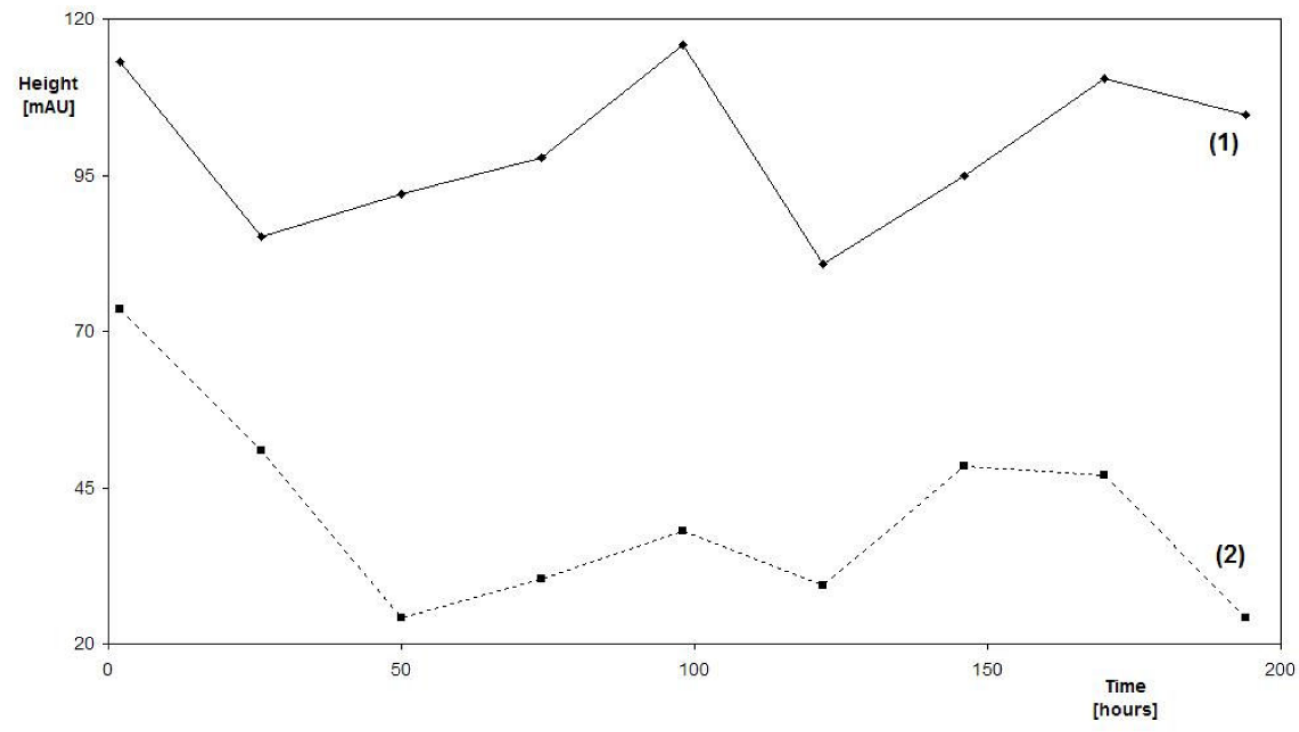

(b)

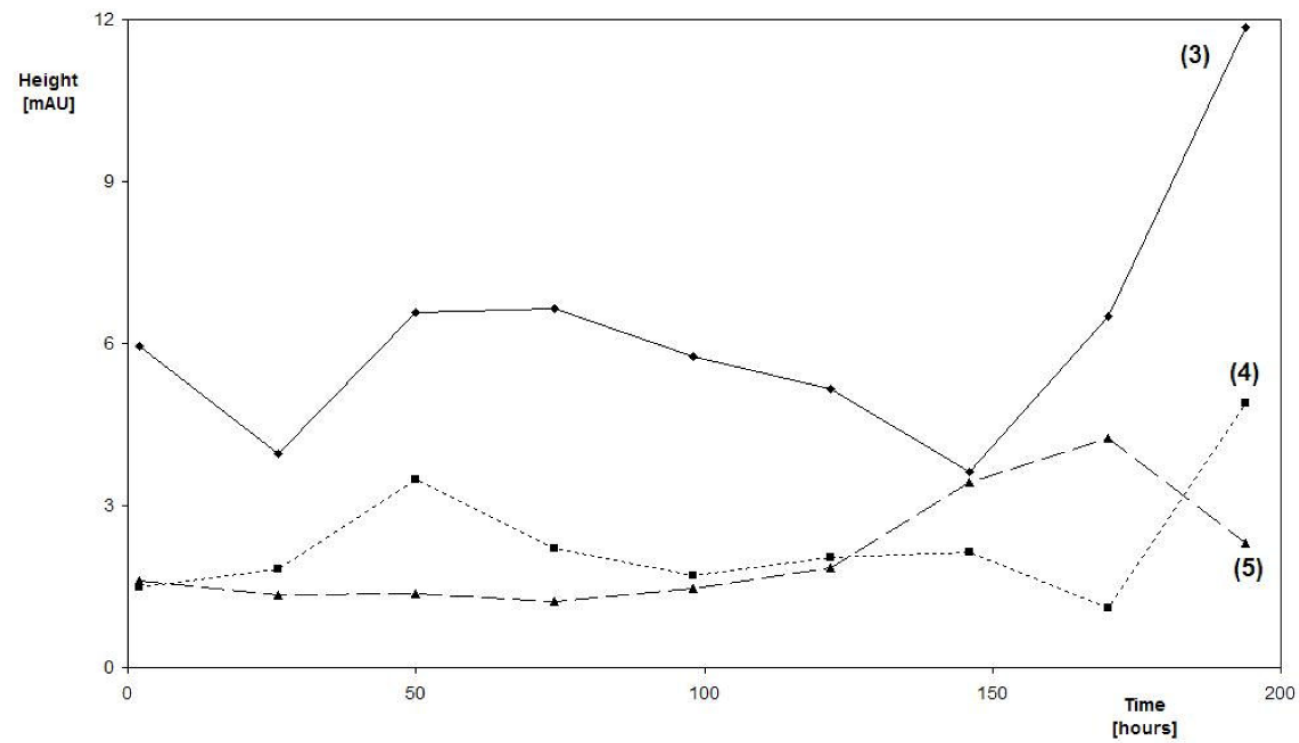

Figure 10 Chromatographic peak heights for (a) peaks 1 and 2, and (b) peaks 3-5 for a rac-phenylglycine solution stored at $22^{\circ} \mathrm{C}$ for nine days. Peak numbers as in Fig. 2. Retention times: peak 1, 5.2 min; peak 2, 5.4 min; peak 3, 5.6 min; peak 4, 6.0 min; peak 5, 6.9 min.

$\mathrm{RS}+\mathrm{R} \stackrel{k 6}{\longrightarrow} \mathrm{S}_{2}$

$\mathrm{SR} \stackrel{k 7}{\longrightarrow} \mathrm{R}_{2}$

$\mathrm{R}_{2} \stackrel{k 8}{\longrightarrow} \mathrm{SR}$

$\mathrm{S}_{2} \stackrel{k 9}{\longrightarrow} \mathrm{RS}$
$\mathrm{RS} \stackrel{k 10}{\longrightarrow} \mathrm{R}+\mathrm{S}$

$$
\mathrm{SR} \stackrel{k 11}{\longrightarrow} \mathrm{R}+\mathrm{S}
$$



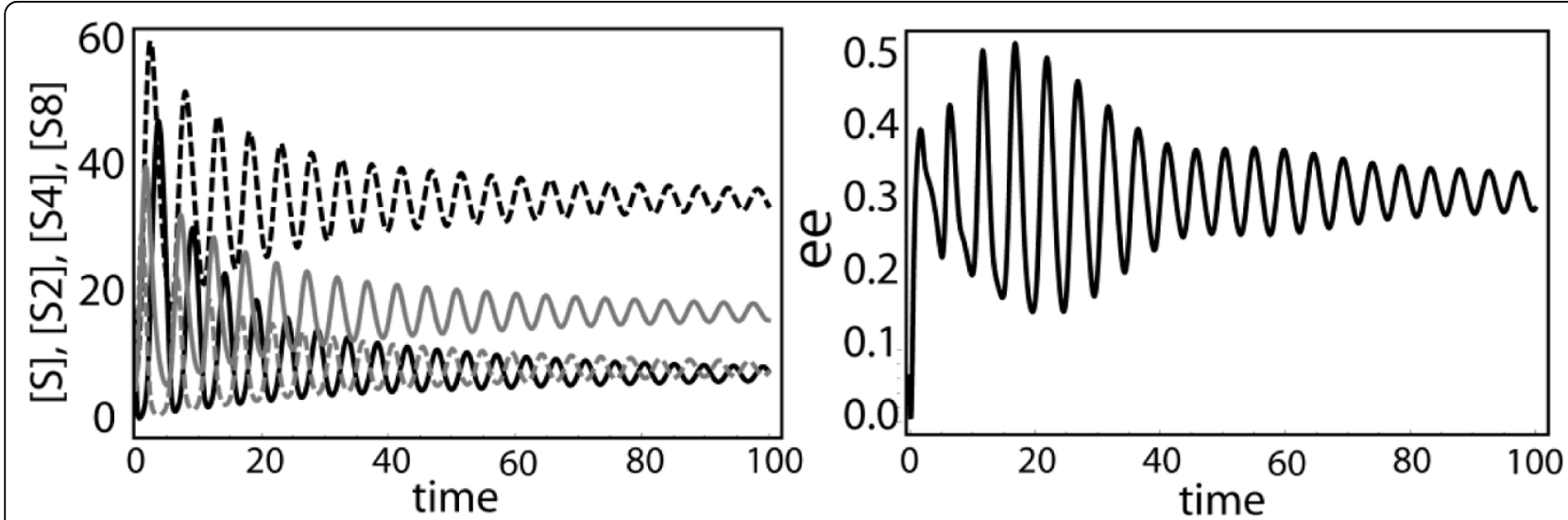

Figure 11 (a) Simulated concentration profiles of $S$ (solid line), $S_{2}$ (dashed line), $S_{4}$ (solid gray line) and $S_{8}$ (dashed gray line) for model $(3-9) k_{1}=k_{2}=k_{3}=k_{4}=1, k_{5}=k_{-5}=0.1, k_{6}=0.001, k_{s}=80$ and $k_{r}=40 ;(b)$ enantiomeric excess, ee $=\left([S]+2\left[S_{2}\right]+4\left[S_{4}\right]+8\left[S_{8}\right]-[R]-\right.$ $\left.2\left[R_{2}\right]-4\left[R_{4}\right]-8\left[R_{8}\right]\right) /\left([S]+2\left[S_{2}\right]+4\left[S_{4}\right]+8\left[S_{8}\right]+[R]+2\left[R_{2}\right]+4\left[R_{4}\right]+8\left[R_{8}\right]\right)$. Initial conditions: $[S]=18$, concentrations of other compounds equal to 6 . Time and concentration units are dimensionless.

$$
\begin{aligned}
& \mathrm{R}_{2} \stackrel{k 14}{\longrightarrow} \mathrm{RS} \\
& \mathrm{S}_{2} \stackrel{k 15}{\longrightarrow} \mathrm{SR}
\end{aligned}
$$

Oscillations appear in this scheme only if the rate constant for formation of heterodimers in steps (20) and (21) is greater than that for homodimers in step (18). The system is closed with respect to mass exchange: $\mathrm{c}=$ $[\mathrm{R}]+[\mathrm{S}]+\left[\mathrm{R}^{*}\right]+\left[\mathrm{S}^{*}\right]+2\left(\left[\mathrm{R}_{2}\right]+\left[\mathrm{S}_{2}\right]+[\mathrm{RS}]+[\mathrm{SR}]\right)=$ const.

In the general case, RS and SR different chemically, so we have: $\mathrm{k}_{4} \neq \mathrm{k}_{5}, \mathrm{k}_{6} \neq \mathrm{k}_{7} \neq \mathrm{k}_{12} \neq \mathrm{k}_{13}, \mathrm{k}_{8} \neq \mathrm{k}_{9} \neq \mathrm{k}_{14} \neq$ $\mathrm{k}_{15}$ and $\mathrm{k}_{10} \neq \mathrm{k}_{11}$. Damped oscillations in a closed

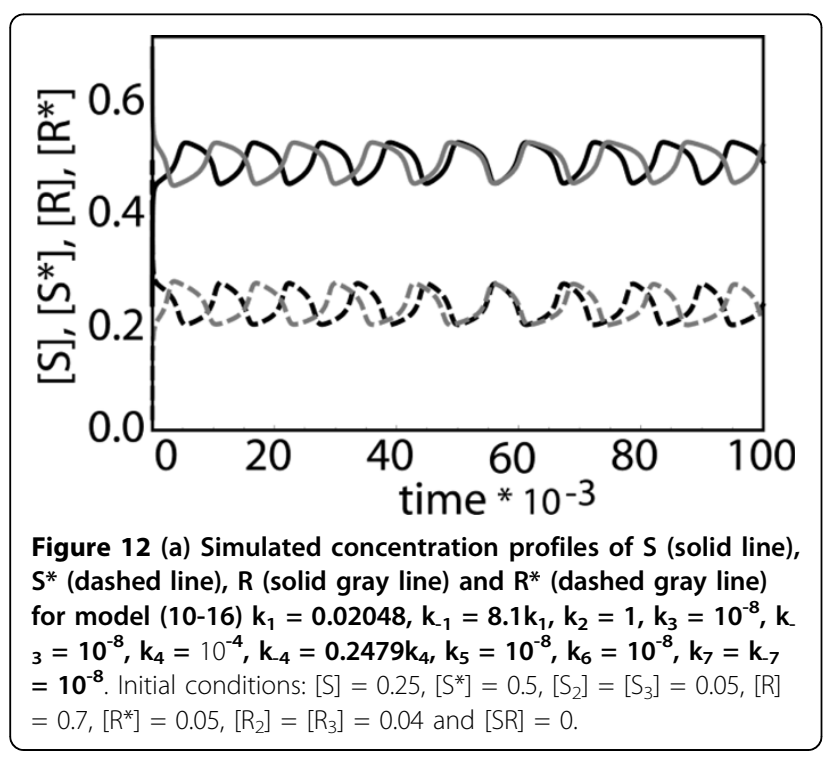

system occur for a broad range of parameters. The dynamics contain a stationary state, which is a stable focus with a negative eigenvalue whose real part is small in magnitude. Such dynamical behavior leads to damped oscillations whose amplitude decreases slowly in time. Results of some simulations are shown in Fig. 13. Concentrations of activated forms of monomers $S^{*}$ and $R^{*}$ (not shown) are about 40 times smaller than concentrations of other species. Generally, activated forms can be detected only in situ because they exist only in the reacting mixture.

\section{Conclusions}

The experimental results presented here demonstrate that phenylglycine, which exists largely in the form of hydrogen-bonded dimers, can undergo a condensation reaction in ethanol-water solution to produce higher oligomers. The reaction occurs in a nonmonotonic fashion and is apparently linked with the oscillatory chiral conversion of amino acids reported previously [4-6]. The S- and Renantiomers appear to differ somewhat in their dynamics, a phenomenon that may arise from the presence of different amounts of trace impurities in the commercial samples. Our observations also suggest that there are two different dimeric aggregates, with one being more reactive with respect to peptidization than the other.

We have briefly presented three approaches to modeling such systems, and in particular to obtaining oscillatory behavior in oligomer populations and enantiomeric excesses. More sophisticated models will need to integrate the various aspects of these processes more seamlessly, but until more detailed kinetic data and rate parameters are available, it seems unwise to attempt to build more specific models. 


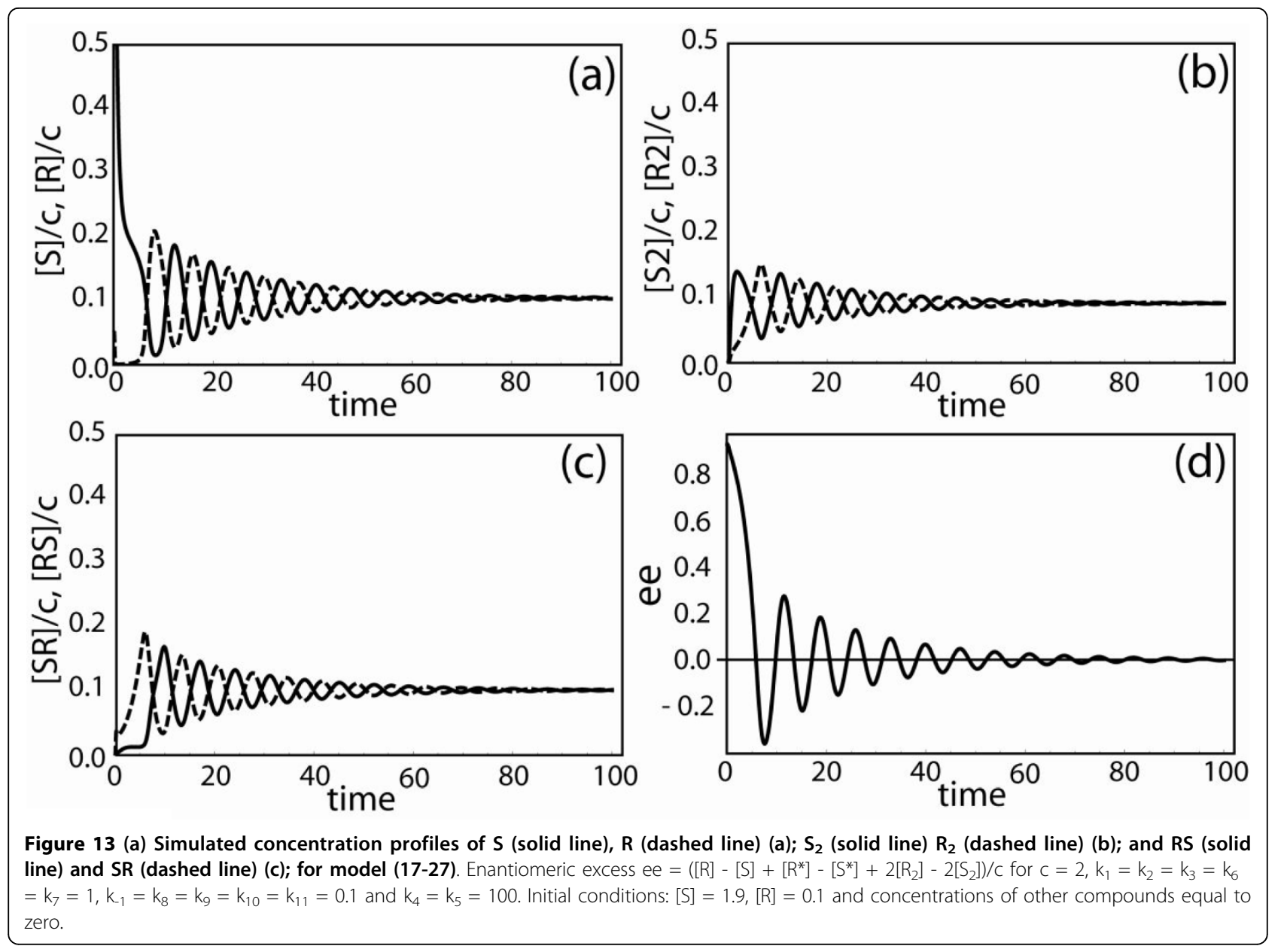

The phenomena we have described may be of considerable importance in processes of chemical self-organization and evolution. While the results and models presented here are relatively crude, they should lay the groundwork for further studies of these fascinating systems.

\section{Acknowledgements}

M.G. and D.K. were partially supported by PhD scholarships within the framework of the "University as a Partner of the Economy Based on Science" (UPGOW) project, subsidized by the European Social Fund (EFS) of the European Union. I.R.E. was supported by the U.S. National Science Foundation grant CHE-0615507.

\section{Author details}

'Institute of Chemistry, University of Silesia, 9 Szkolna Street, 40-006 Katowice, Poland. ${ }^{2}$ Chemistry Department, MS 015, Brandeis University, Waltham, MA 02454-9110, USA. ${ }^{3}$ Institute of Physical Chemistry, Polish Academy of Sciences, Kasprzaka 44/52, 01-224 Warsaw, Poland.

\section{Authors' contributions}

MS and TK designed the experiments. MS, MG and DK performed the experiments. ML designed the models and carried out the simulations. TK and ML drafted the manuscript. IRE integrated the experiments and simulations and wrote the final manuscript. All authors read and approved the final manuscript.

\section{Competing interests}

The authors declare that they have no competing interests.

Received: 9 April 2010 Accepted: 18 August 2010

Published: 18 August 2010

\section{References}

1. Sajewicz M, Piętka R, Pieniak A, Kowalska T: Application of thin-layer chromatography (TLC) to investigating oscillatory instability of the selected profen enantiomers. Acta Chromatogr 2005, 15:131-149.

2. Sajewicz M, Gontarska M, Wróbel M, Kowalska T: Enantioseparation and oscillatory transenantiomerization of $S, R-( \pm)$-ketoprofen, as investigated by means of thin layer chromatography with densitometric detection. $J$ Liq Chromatogr Relat Technol 2007, 30:2193-2208.

3. Sajewicz M, Gontarska M, Kronenbach D, Wojtal $Ł$, Grygierczyk G, Kowalska T: Study of the oscillatory in vitro transenantiomerization of the antimers of flurbiprofen and their enantioseparation by thin-layer chromatography (TLC). Acta Chromatogr 2007, 18:227-238.

4. Sajewicz M, Kronenbach D, Gontarska M, Kowalska T: TLC and polarimetric investigation of the oscillatory in-vitro chiral inversion of $L$-alanine. J Planar Chromatogr Modern TLC 2008, 21:43-47.

5. Sajewicz M, Gontarska M, Wojtal $Ł$, Kronenbach D, Leda M, Epstein IR, Kowalska T: Experimental and model investigation of the oscillatory transenantiomerization of $L-\alpha$-phenylalanine. J Liq Chromatogr Relat Technol 2008, 31:1986-2005.

6. Sajewicz M, Kronenbach D, Staszek D, Wróbel M, Grygierczyk G, Kowalska T: Experimental investigation of the oscillatory transenantiomerization of $L$ tyrosine. J Liq Chromatogr Relat Technol 2008, 31:2006-2018. 
7. Sajewicz M, John E, Kronenbach D, Gontarska M, Kowalska T: TLC study of the separation of the enantiomers of lactic acid. Acta Chromatogr 2008, 20:367-382.

8. Sajewicz M, Kronenbach D, Gontarska M, Wróbel M, Piętka R, Kowalska T: TLC in search for structural limitations of spontaneous oscillatory in-vitro chiral conversion. $\alpha$-Hydroxybutyric and mandelic acids. J Planar Chromatogr Modern TLC 2009, 22:241-248.

9. Belanger P, Atkinson JG, Stuart RS: Exchange reactions of carboxylic acid salts. Kinetics and mechanism. Chem J Chem Soc D: Commun 1969, 1067-1068.

10. Xie Y, Liu H, Chen J: Kinetics of base catalyzed racemization of ibuprofen enantiomers. Int J Pharm 2000, 196:21-26.

11. Sajewicz M, Matlengiewicz M, Leda M, Gontarska M, Kronenbach D, Kowalska T, Epstein IR: Spontaneous oscillatory in vitro chiral conversion of simple carboxylic acids and its possible mechanism. J Phys Org Chem .

12. Sajewicz M, Wrzalik R, Gontarska M, Kronenbach D, Leda M, Epstein IR, Kowalska T: In vitro chiral conversion, phase separation, and wave propagation in aged profen solutions. J Liq Chromatogr Relat Technol 2009, 32:1359-1372.

13. Peacock-López E, Radov DB, Flesner CS: Mixed-mode oscillations in a selfreplicating dimerization mechanism. Biophys Chem 1997, 65:171-178.

14. Tsai LL, Hutchinson GR, Peacock-López E: Turing patterns in a selfreplicating mechanism with a self-complementary template. $J$ Chem Phys 2000, 113:2003-2006.

15. Plasson R, Bersini H, Commeyras A: Recycling Frank: Spontaneous emergence of homochirality in noncatalytic systems. Proc Nat Acad Sci USA 2004, 101:16733-16738.

16. Sajewicz M, Gontarska M, Kronenbach D, Kowalska T: On the spontaneous abiotic peptization of phenylglycine in an aqueous medium. Acta Chromatogr 2009, 21:151-160.

17. Sajewicz M, Matlengiewicz M, Kronenbach D, Gontarska M, Kowalska T: On the spontaneous condensation of selected hydroxy acids. Acta Chromatogr 2009, 21:259-271.

18. Matlengiewicz M, Sajewicz M, Gontarska M, Kronenbach D, Kowalska T: On the spontaneous condensation of profens, with ketoprofen as an example. Acta Chromatogr 2010, 22:81-90.

19. Ivanov PV, Maslova VI, Bondareva NG, Yur'eva OA, Kozlova NV, Chernyshev EA, Odintsov KYu, Zykunova EA: Concentration oscillations in the condensation of organosilanols. Russ Chem Bull 1997, 46:2138-2141.

20. Chernyshev EA, Ivanov PV, Golubykh DN: Inteermediates of chemical assembling of oligoorganosiloxanes in hydrolysis of organochlorosilanes. Russ Chem Bull 2001, 50:1998-2009.

21. Blackmond DG: Mechanistic study of the Soai autocatalytic reaction informed by kinetic analysis. Tetrahedron: Asymmetry 2006, 17:584-589.

22. Mickskei K, Rábai G, Gál E, Caglioti L, Pályi G: Oscillatory symmetry breaking in the Soai reaction. J Phys Chem B 2008, 112:9196-9200.

23. Bradford MM: A rapid and sensitive method for the quantitation of microgram quantities of protein utilizing the principle of protein-dye binding. Anal Biochem 1976, 72:248-254.

24. Hyver C: Generation of oscillations in polymerization-depolymerization systems. J Chem Phys 1985, 83:850-851.

25. Bykov VI, Gorban AN: A model of autooscillations in association reactions. Chem Eng Sci 1987, 42:1249-1251. 